\title{
Modeling and Analysis of Canal Type Small Hydro Power Plant and Performance Enhancement Using PID Controller
}

\author{
Rayes Ahmad Lone (Assistant Professor) \\ Department of Electrical Engineering, Islamic University of Science and Technology, Awantipora, Pulwama, \\ Jammu and Kashmir 192221, India
}

\begin{abstract}
In this paper, the simulation model of a typical canal type small hydroelectric power plant was developed through interconnection of models of various equipments of the plant under consideration in a MATLAB/Simulink based software environment. The various components of small hydroelectric plant like open channel, governor and Semi-Kaplan turbine, synchronous generator, exciter are being considered under modeling and simulation.. The aim is to study its behavior during transient condition. Using the simulated model enhancement through PID controller will be done to reduce oscillations, peak overshoot and peak undershoot during transient period and also to improve the steady state response This study helps in verifying costs and safety conditions, in selecting the best alternatives in the early phase of design and to determine the requirements of special protection devices.
\end{abstract}

Keywords - Hydraulic Transients, mathematical models, proportional and integral controller, small hydro electric power plants, Matlab/Simulink.

\section{INTRODUCTION}

In Irrigation canal based Small Hydro plants, utilizing the heads available gives more or less constant power generation. But it is seen that the head available is almost constant whereas there are large variations in the discharge available. The power generation is completely dependent upon irrigation releases season wise through the canal which depends upon the crop pattern in the region. Power generation is for nine months as months of April, May and August are not considered since discharge is less than 1 cumecs.

Modeling and simulation of small hydro power plant is valuable tool for planning power plant operations and judging the value of physical improvement by selecting proper system parameters. Earlier this was done for large or small hydro power plants. But for canal type small hydro power plants this study helps in verifying costs and safety conditions. It also helps in verifying the parameters of control equipments like water level regulator, governor, exciter etc. and in determining the dynamic forces acting on the system which must be considered in structural analysis of the penstock and their support.

\section{Mathematical Modeling}

Generally differential equations are used to describe the various power system components. Study of the dynamic behavior of the system depends upon the nature of the differential equations.

Small System: If the system equations are linear, the techniques of linear system analysis are used to study dynamic behavior. Each component is simulated by transfer function and these transfer functions blocks are connected to represent the system under study.

Large System: Here state-space model will be used for system studies described by linear differential equations. However for transient stability study the nonlinear differential equations are used.

\section{Methods used for modeling for Canal Type Small Hydro Power Plant.}

1.1 The generator model is derived starting from the basic circuit equations and the use of Park's transformation.

1.2 Hydraulic turbine model includes both linear and nonlinear control methods. Nonlinear models are required where speed and power changes are large.

1.3 For governor, mathematical equations of ordinary differential equations representing the dynamic behavior are used. Here the regulator consists of two parts electrical (PID Controller) and electro-hydraulic parts

1.4 For exciters ordinary differential equations are used.

\section{Mathematical Modeling of a Synchronous Machine:}

The synchronous machine under consideration is assumed to have three stator windings, one field winding and two damper windings. 


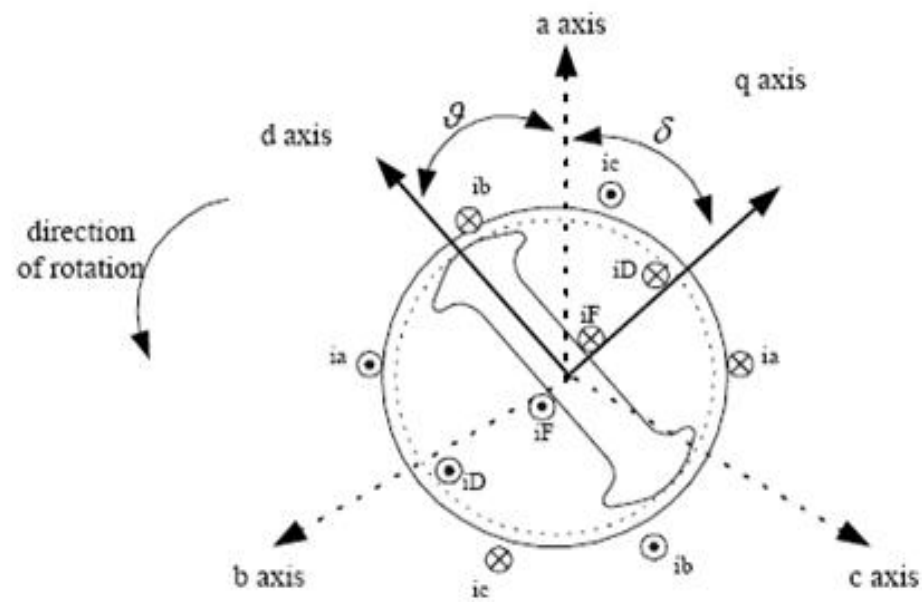

Fig. 1: Representation of a synchronous machine

Equation (1) is the generator voltage equation in the rotor frame of reference is described in Per-unit. The machine equation in the rotor frame of reference becomes.

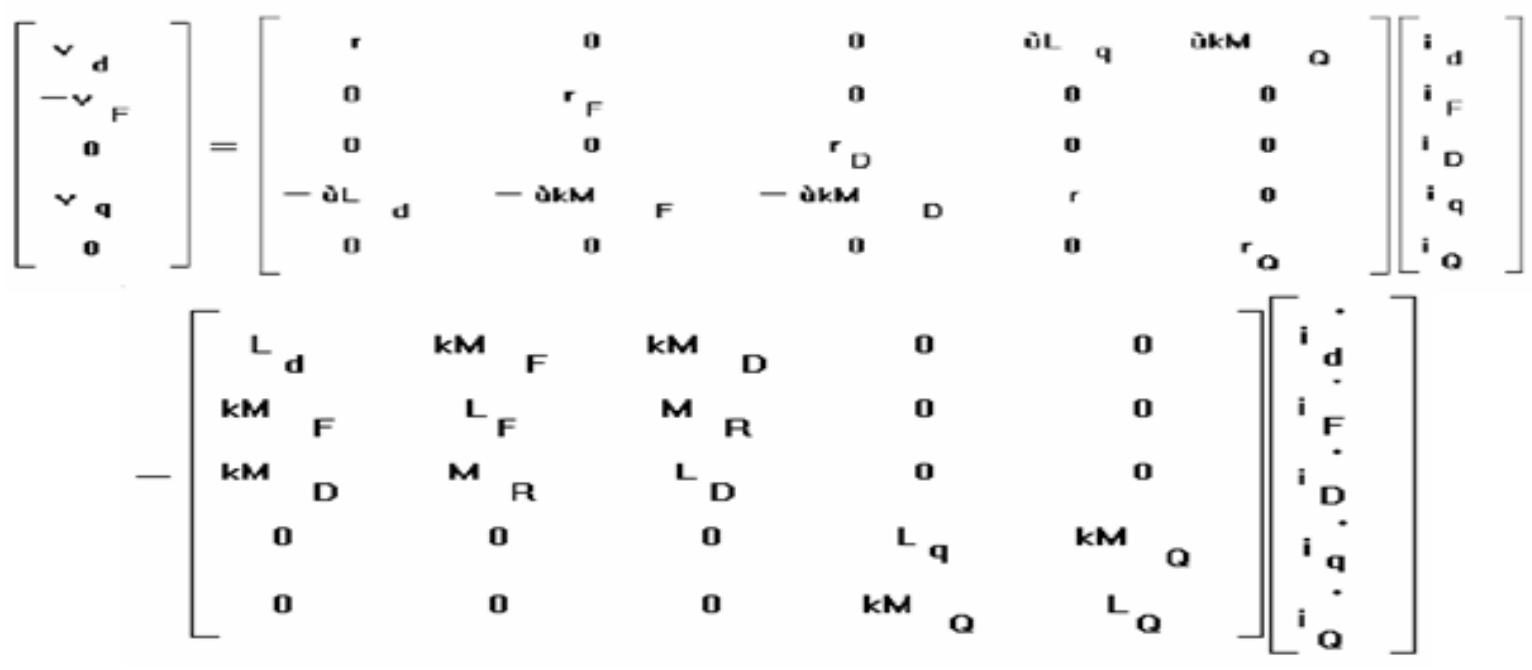

(1)

Where,

$L_{d}=$ Equivalent direct-axis Reactance

$L_{F}=$ Filed winding Self - inductance

$L_{D}=$ Self-inductance damper winding

$L_{q}=$ Equivalent quadrature axis reactance

$L_{Q}=$ Self inductance of quadrature reactance

$K_{M D}=$ Stator to damper winding resistance

$K_{M Q}=$ Stator to quadrature winding resistance

$r=$ Stator winding current

$r_{F} \quad=$ Field winding resistance

$r_{D}=$ resistance of $\mathrm{d}$ axis damper winding

$r_{Q}=$ resistance of $\mathrm{q}$ axis damper winding

$i_{q}=$ armature current in the $\mathrm{q}$ direction

$i_{F}=$ Field current

$i_{D}=\mathrm{d}$ axis damper winding current

$i_{d}=\mathrm{q}$ axis damper winding current 


\section{Modeling of Hydraulic Turbine and Governing System.}

3.1 Hydraulic Turbine Modeling

The representation of the hydraulic turbine and water column in stability studies is usually based on the following assumptions:

1. The hydraulic resistance is negligible.

2. The penstock pipe is inelastic and the water is incompressible.

3. The velocity of the water varies directly with the gate opening and with square root of the net head. The turbine output power is proportional to the product of head and volume flow.

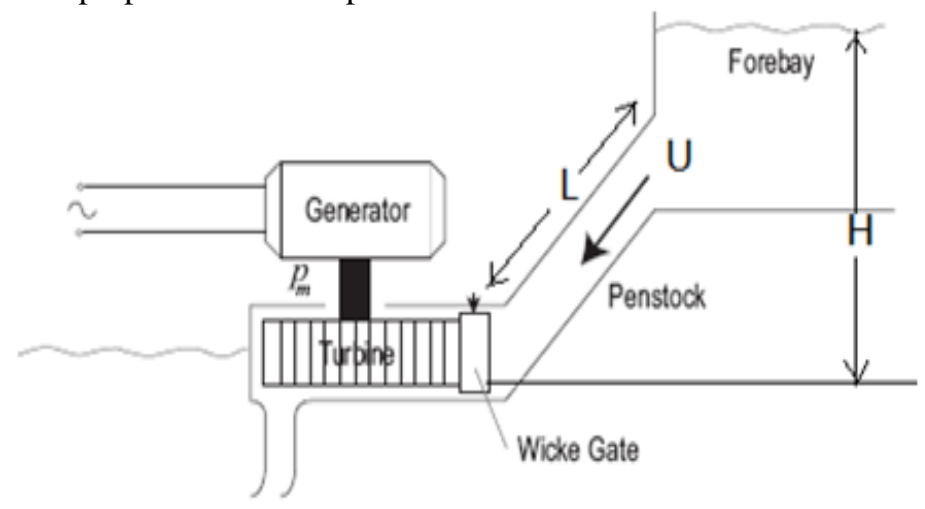

Fig. 2: A Typical Control System of Hydroelectric Plant

The velocity of the water in the penstock is given by

Where

$$
\mathrm{U}=K_{u} \mathrm{G} \sqrt{\mathrm{H}}
$$

$$
\begin{aligned}
& \mathrm{U}=\text { water velocity } \\
& \mathrm{G}=\text { gate position } \\
& \mathrm{H}=\text { hydraulic head at gate } \\
& K_{u}=\text { a constant of proportionality }
\end{aligned}
$$

$$
\frac{\Delta \dot{\mathrm{P} m}}{\Delta \overline{\mathrm{G}}}=\frac{1-T_{W} \mathrm{~s}}{1+0.5 T_{W} s}
$$

Above equation represents the classical transfer function of a hydraulic turbine. It shows how the turbine power output changes in response to a change in gate opening for an ideal lossless turbine. Fig. 3 shows the mathematical model.

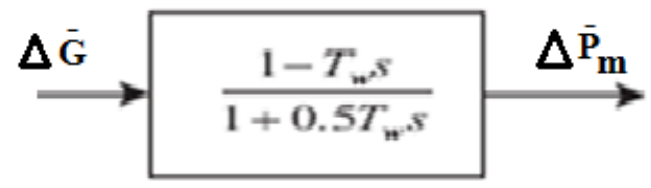

Fig. 3: Mathematical model of hydraulic turbine

\subsection{Governor Modeling:}

The basic function of a governor is to control speed and/or load. The primary speed/load control function involves feeding back speed error to control the gate position. In order to ensure satisfactory and stable parallel operation of multiple units, the speed governor is provided with a droop characteristic. The purpose of the droop is to ensure equitable load sharing between generating units. For stable control performance, a large transient droop with a long resetting time is therefore required. This is accomplished by the provision or a rate feedback or transient gain reduction compensation as shown in the figure. 


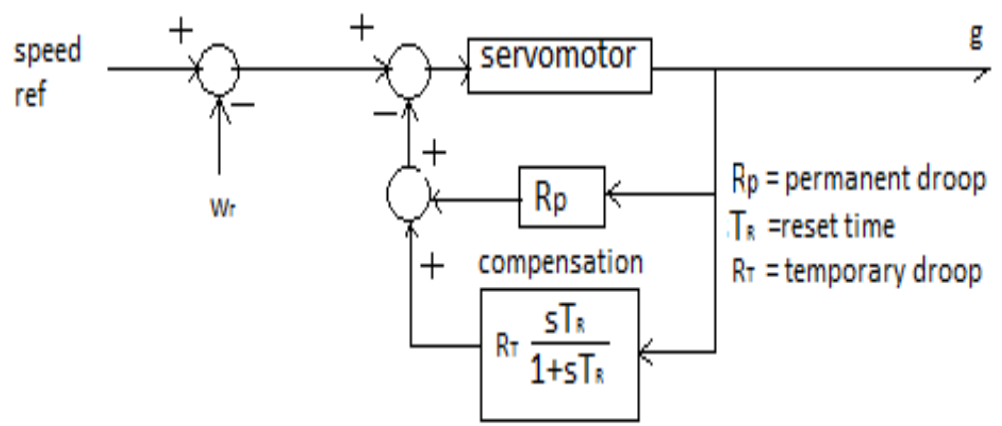

Fig. 4: Governor with transient droop compensation

\subsection{Mechanical-hydraulic governor model:}

The various components of Mechanical-hydraulic governor are; speed sensing, permanent droop feedback, computing functions, relay valve, gate servomotor and a dashpot used to provide transient droop compensation.

The transfer function of the relay valve and gate servomotor is

The transfer function of the pilot valve and pilot servo is

$$
\begin{aligned}
& \frac{\mathrm{g}}{\mathrm{a}}=\frac{\mathrm{K}_{1}}{\mathrm{~S}} \\
& \text { pilot servo is } \\
& \frac{\mathrm{a}}{\mathrm{b}}=\frac{\mathrm{K}_{2}}{1+S \mathrm{~S}_{\mathrm{p}}}
\end{aligned}
$$

Where $K_{2}$ is determined by the feedback lever ratio; $T_{p}$ by port areas of the pilot valve and $K_{2}$. Now from above two equations we have

$$
\frac{\mathrm{g}}{\mathrm{b}}=\frac{\mathrm{K}_{1} \mathrm{~K}_{2}}{\mathrm{~s}\left(1+\mathrm{s} \mathrm{T}_{\mathrm{p}}\right)}=\frac{\mathrm{K}_{\mathrm{s}}}{\mathrm{s}\left(1+\mathrm{sT} \mathrm{T}_{\mathrm{p}}\right)}
$$

Where $K_{s}$ is the servo gain.

The transfer function of the dashpot is given by

$$
\frac{\mathrm{d}}{\mathrm{g}}=\mathrm{R}_{\mathrm{T}} \frac{\mathrm{sT}_{\mathrm{R}}}{\mathrm{s}\left(1+\mathrm{s} \mathrm{T}_{\mathrm{R}}\right)}
$$

The temporary droop $R_{T}$ is determined by the lever ratio, and the reset/washout time $T_{R}$ is determined by needle valve setting. below.

A block diagram representation of the governing system suitable for system stability studies is shown

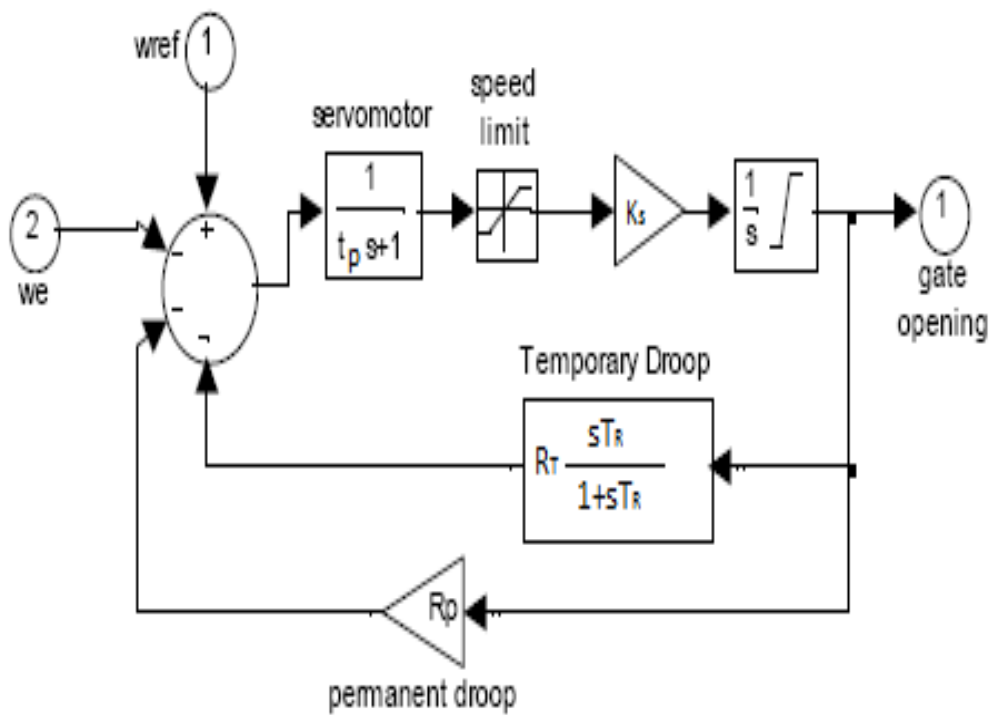

Fig. 4: Shows the Model of governors for hydraulic-turbines

\section{Excitation System Modeling:}

The basic elements which form different types of excitation systems are the dc or ac exciters, rectifiers, amplifiers, stabilizing feedback circuits, signal sensing and processing circuits. 

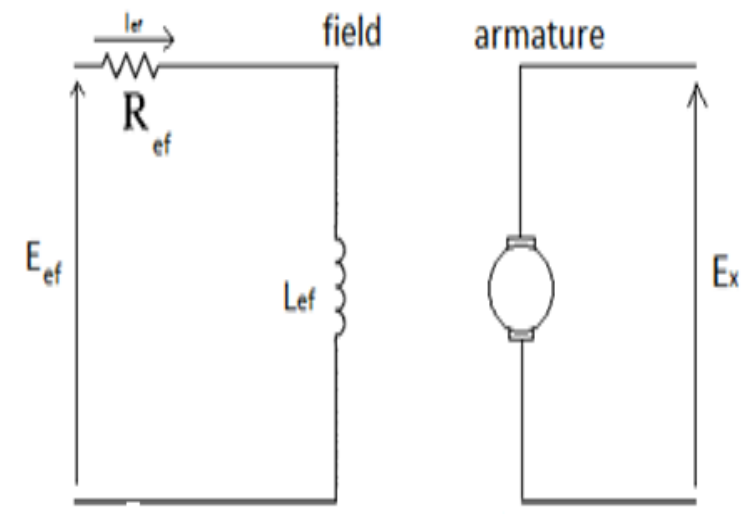

Fig. 5: Separately Excited DC Exciter

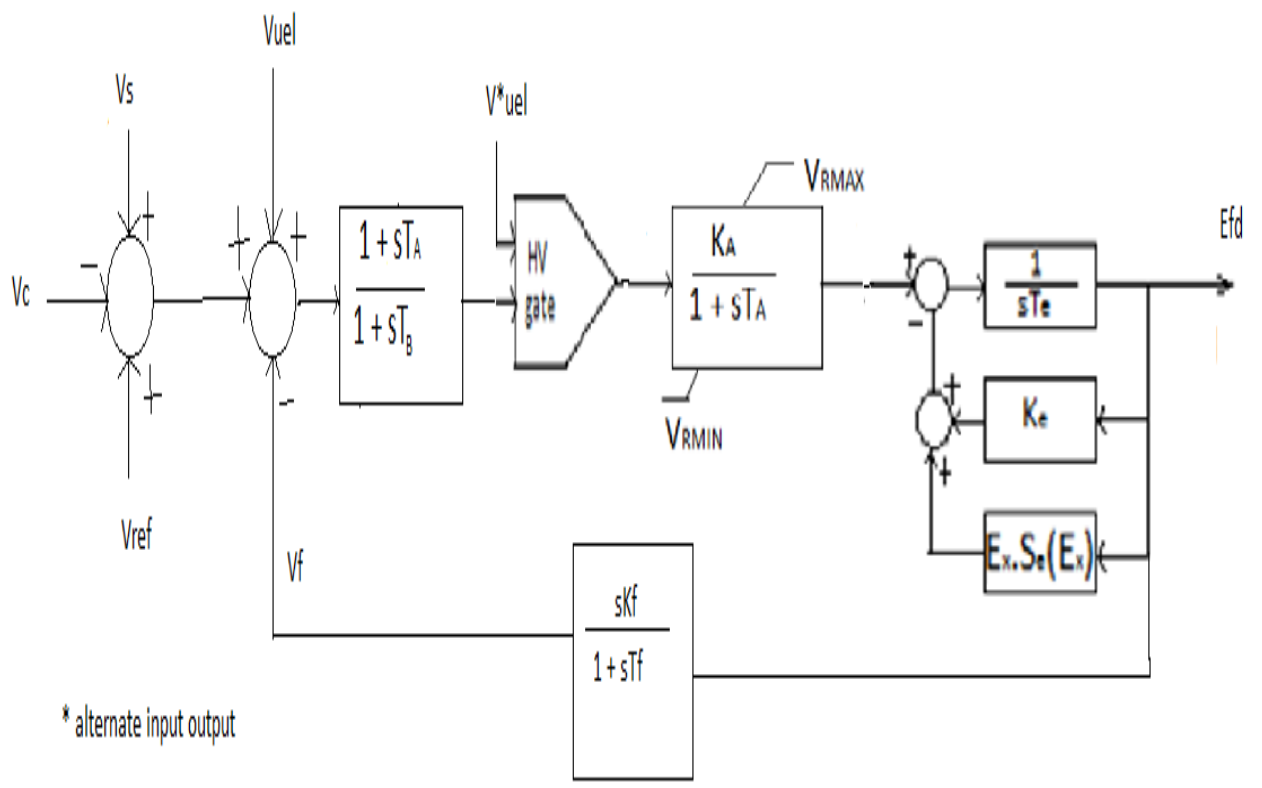

Fig. 6: Excitation system with stabilizing circuit

\section{Simulation Model Developed In A Matlab/Simulink Software Environment.}

The entire simulation system for the analysis of hydraulic transients in a hydroelectric power plant has been developed in a MATLAB/Simulink based software environment. Subsystems have been utilized in the simplification of a system diagram and the creation of reusable systems. Further, a subsystem is a group of blocks that is represented by a subsystem block. The entire simulation system contains three subsystems: first, the speed governor and servomechanism, in which turbine speed, dead zone, valve saturation, and limitation are all considered; second: the hydrodynamics system (HS), which consists of tunnels, penstock, and surge tanks; and third, the turbine generator and network, which has a generator unit operating in isolation. The combination of three subsystems are shown in Fig. 7. 
Normal working Model for Canal Drop Hydro Power Plant

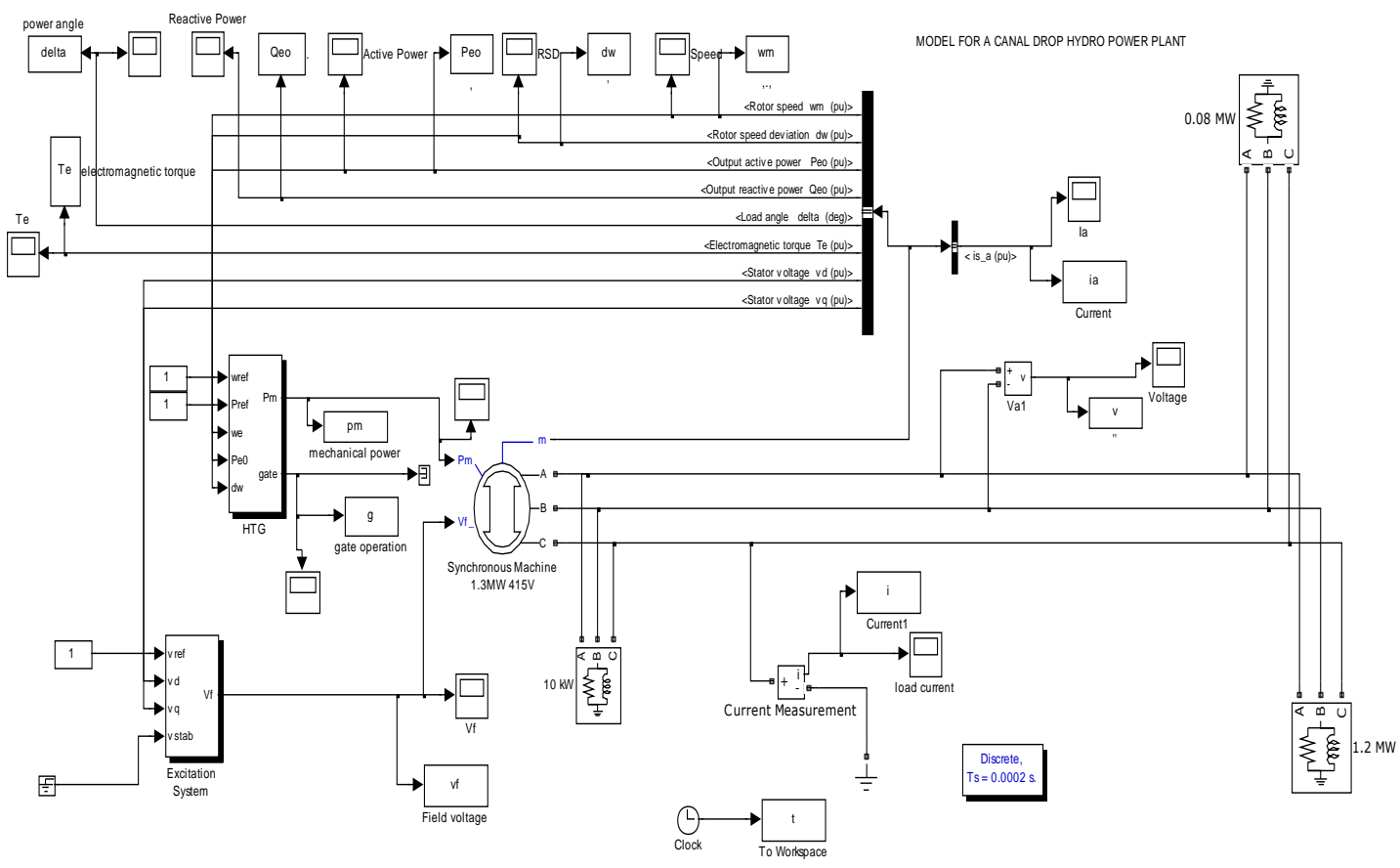

Fig. 7: Working model for canal type hydro power plant

PERFORMANCE ENHANCEMENT OF THE PLANT USING PID CONTROLLER

PERFORMANCE ENHANCEMENTOF THE PLANT USING PID CONTROLLER

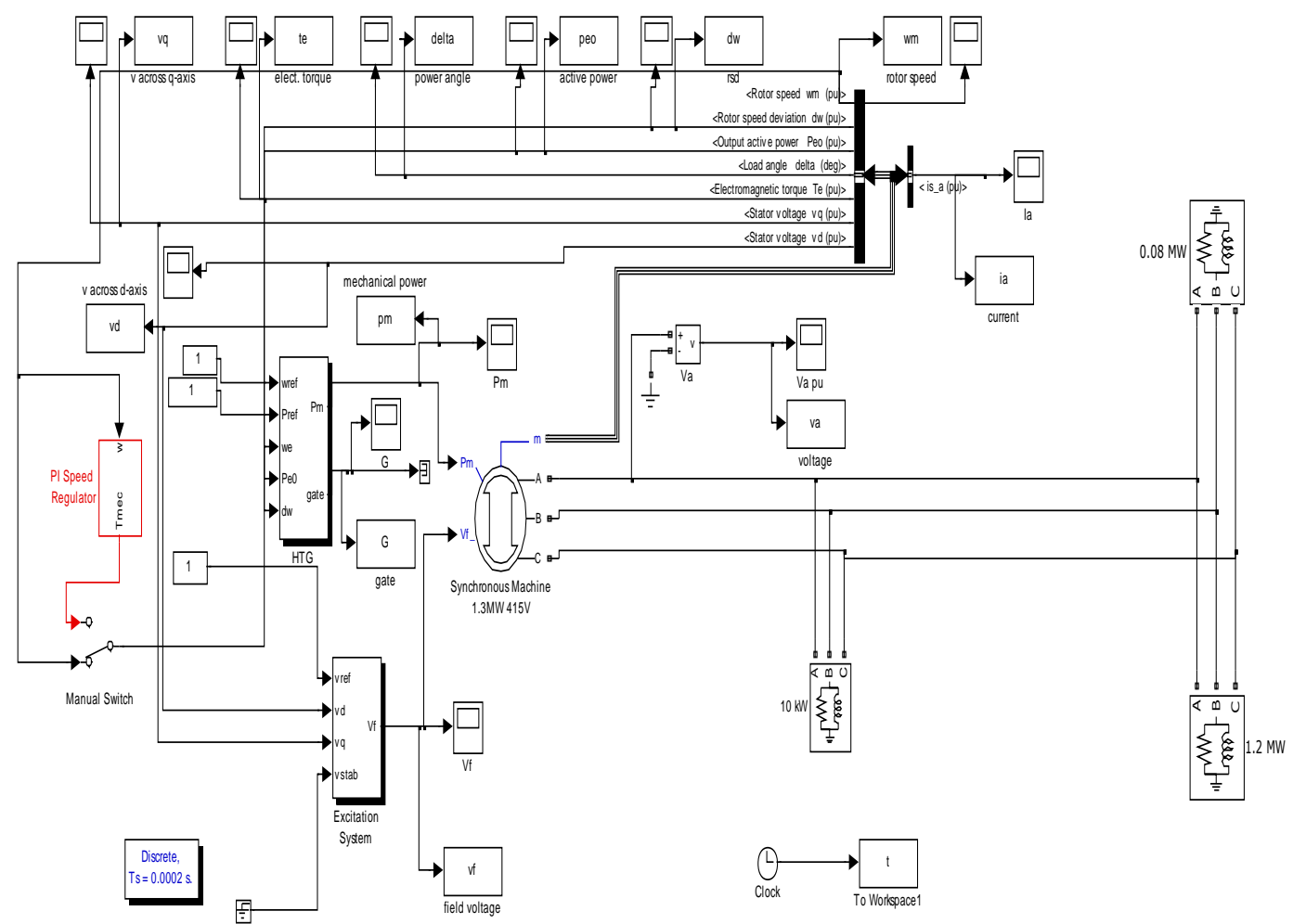

Fig.8: Working model for canal type hydro power plant 
A typical canal based hydroelectric power plant with a Kaplan turbine, as shown in Fig. 7 reflects the Canal Hydro Power Plant in Bathinda Punjab run under Punjab Energy Development Agency (PEDA), and hence all the data of this plant are used to simulate hydraulic transients for different changes. Therefore, all of these simulations are performed on different operating conditions. In addition, the influences of changing different parameters of pressure water supply system, turbine speed governor PID gains, as well as surge tanks were analyzed. The simulation results are all in per unit system and the required data are below

\subsection{Turbine and Governor Data}

$\begin{array}{ll}\mathrm{h} & =2.10 \\ \mathrm{~h}_{\text {char }} & =2.74 \\ \mathrm{~T}_{w} & =3 \\ \omega & =93 \mathrm{rpm} \\ \eta_{t} & =91 \% \\ \omega_{\text {ref }} & =1 \mathrm{p} . \mathrm{u} . \\ \mathrm{T}_{a} & =0.07 \\ \mathrm{R}_{p} & =0.05 \\ \mathrm{~K}_{p} & =3 \\ \mathrm{~K}_{i} & =0.10 \\ \mathrm{~K}_{d} & =3.26 \\ \mathrm{~T}_{d} & =0.02 \\ \mathrm{~K}_{a} & =10 / 3 \\ \mathrm{~g}_{\min } & =0.01 \\ \mathrm{~g}_{\max } & =0.97518 \\ \mathrm{v}_{\min } & =-0.1 \\ \mathrm{v}_{\max } & =0.1\end{array}$

\subsection{Exciter}

$\mathrm{V}_{\text {ref }} \quad=1$

$\mathrm{V}_{\text {ter }} \quad=1$

$\mathrm{T}_{c}$ and $\mathrm{T}_{d} \quad=0.00001,0.00001$

$\mathrm{T}_{e} \quad=0.08$

$\mathrm{V}_{\text {rmax }} \quad=-15$

$\mathrm{V}_{\text {rmin }} \quad=7.3$

$\mathrm{T}_{r} \quad=0.87$

$\mathrm{K}_{a} \quad=200$

$\mathrm{T}_{a} \quad=0.02$

$\mathrm{K}_{e} \quad=1$

$\mathrm{K}_{f} \quad=0.03$

$\mathrm{T}_{f} \quad=1$

$\mathrm{V}_{f} \quad=1.2911$

\subsection{Synchronous Generator}

$\begin{array}{ll}\mathrm{P}_{n} & =1.3 \mathrm{MW} \\ \mathrm{V}_{n} & =415 \mathrm{~V} \\ \mathrm{f} & =50 \\ \mathrm{X}_{d} & =0.911 \\ \mathrm{X}_{d}^{\prime} & =0.408 \\ \mathrm{X}_{d}^{\prime \prime} & =0.329 \\ \mathrm{X}_{q} & =0.580 \\ \mathrm{X}_{q}^{\prime \prime} & =0.350 \\ \mathrm{X}_{1} & =0.3 \\ \mathrm{~T}_{d}^{\prime} & =0.7 \\ \mathrm{~T}_{d}^{\prime \prime} & =0.035 \\ \mathrm{~T}_{q 0}^{\prime \prime} & =0.033 \\ \mathrm{R}_{s} & =0.03 \\ \mathrm{H}^{\prime} & =1\end{array}$


$\mathrm{P}$

$\mathrm{V}_{f}$
$=4$

$=1$

\subsection{PID Controller}

$\begin{array}{ll}\mathrm{K}_{p} & =0.01 \\ \mathrm{~K}_{i} & =-0.88 \\ \mathrm{~K}_{d} & =0\end{array}$

\section{Conclusion}

In this case, synchronous generator is connected to the load through a transmission line as shown in Fig.7. The load is $1.2 \mathrm{MW}$ on the generator. As the oscillations during the transient period is very large for mechanical input and in gate operation of the generator. To reduce their these oscillations into a limited range, a PID controller was used. The values of the governor, exciter, synchronous generator and hydraulic turbine are same as given before. The corresponding results are shown between figures 9 and 10 .
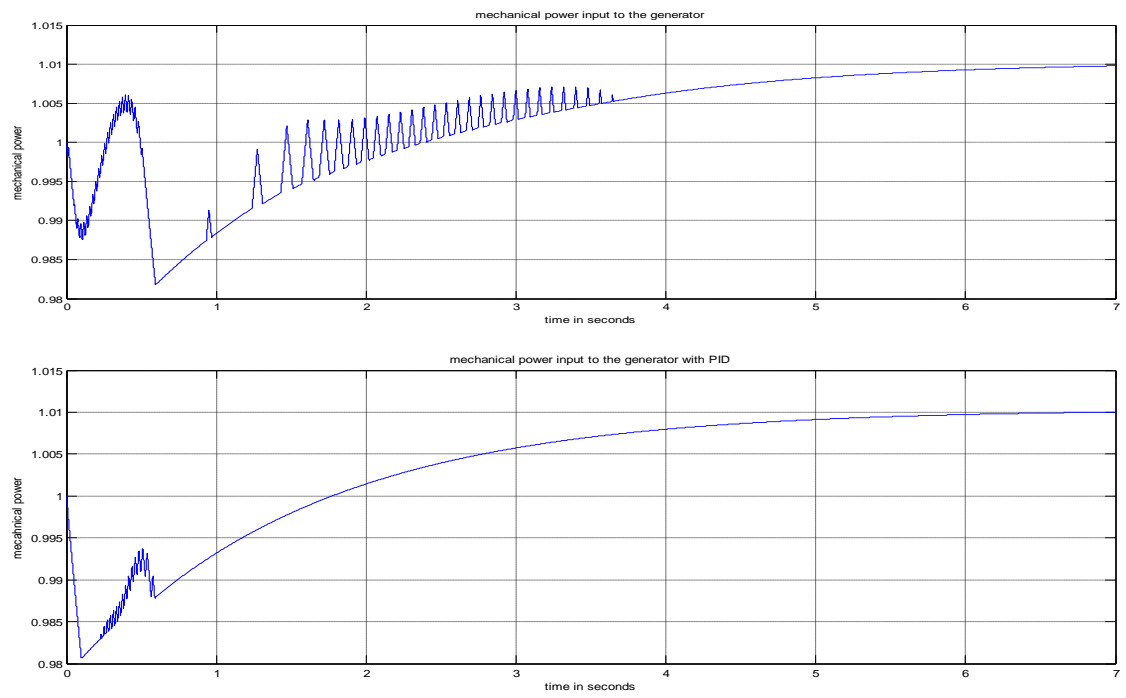

Mechanical Power Vs Time
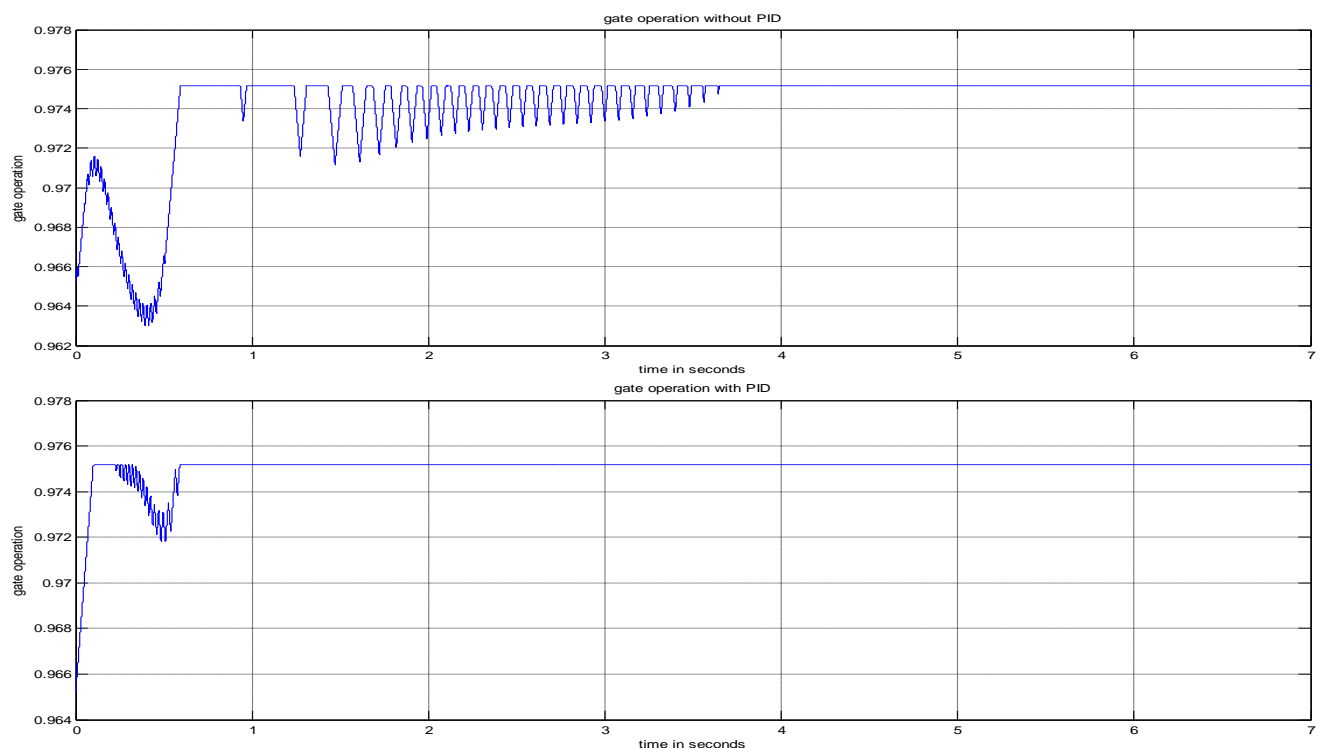

Fig. 10 Gate Operation Vs Time 


\section{Table -1 Experiment Result}

\begin{tabular}{|c|c|c|}
\hline Quantity & Without PID & With PID \\
\hline $\begin{array}{c}\text { Mechanical Power } \\
\text { Oscillations duration during } \\
\text { Transient Period }\end{array}$ & Upto $3.5 \mathrm{sec}$ & Upto $0.05 \mathrm{sec}$ \\
\hline $\begin{array}{c}\text { Maximum Overshoot for } \\
\text { Mechanical Power }\end{array}$ & $1.006 \mathrm{pu}$ & 0.994 \\
\hline $\begin{array}{c}\text { Maximum Undershoot for } \\
\text { Gate Opening }\end{array}$ & $0.963 \mathrm{pu}$ & $0.971 \mathrm{pu}$ \\
\hline Steady State Response & 3.7 seconds & 0.6 seconds \\
\hline
\end{tabular}

When the plant was connected to its load, there has been a lot of oscillations in the mechanical power (input to the generator) and in the gate operation during the initial transient period as convenient from the waveforms. By using the PID controller, the oscillations in the mechanical power and in gate opening during the transient period was drastically reduced. Whereas maximum overshoot and maximum undershoot was also controlled. For mechanical power the steady state reached in less than 0.5 seconds as compared without PID controller where steady state was reached after 3.7 seconds. We can say that there was no oscillations during the transient period. Same case happened with the gate operation, there was very low oscillations in its operation during the transient period, when PID was put in operation.

\section{References}

[1] Carmen L.T. Borges, Senior Member, IEEE, and Roberto J. Pinto. Small Hydro Power Plants Energy Availability Modeling for Generation Reliability Evaluation. IEEE TRANSACTIONS ON POWER SYSTEMS, VOL. 23, NO. 3, AUGUST 2008.

[2] National Association of State Energy Officials (NASEO). Web site: www.naseo.org

[3] Micro-hydro. Web site: www.geocities.com/wim klunne/hydro/index.html

[4] U.S. Department of Energy Hydropower Program. Web site: hydropower.inel.gov

[5] Volunteers in Technical Assistance (VITA). Web site: www.vita.org

[6] Energy Efficiency and Renewable Energy Clearinghouse (EREC). Web site: www.eren.doe.gov/consumerinfo/.

[7] Prabha Kundur, Power System Stability and Control by Tata McGraw-Hill, New York. A Power System Engineering Series.

[8] Paul M. Anderson and A.A. Fouad Power System Control and Stability IEEE PRESS. The Institute of Electrical and Electronics Engineer, Inc., New York.

[9] K.R.Padiyar, Power System Dynamics-Control and Stability, Interline Publishing Pvt. Ltd., Banglore.

[10] Hongqing Fang, Long Chen, Nkosinathi Dlakavu, and Zuyi Shen Basic Modeling and Simulation Tool for Analysis of Hydraulic Transients in Hydroelectric Power Plants. IEEE Transactions on Energy Conversion, Vol. 23, No. 3, September 2008.

[11] FANG Hong-qing, Student Member, IEEE, and SHEN Zu-yi. Modeling and Simulation of Hydraulic Transients for Hydropower Plants. 2005 IEEE/PES Transmission and Distribution Conference \& Exhibition: Asia and Pacific Dalian, China.

[12] GE Baojun, XIN Peng and LV Yanling. The Excitation System Simulation of Huge Hydro-generator. Harbin University of Science and Technology Harbin, China, E-mail: Gebj@ hrbust.edu.cn, xinpeng4321@ sina.com, 978-1-4244-4813-5/10/\$25.00 @2010 IEEE.

[13] Fang Yang Hao Lei Yuanzhang Sun Wei Lin and Tielong Shen. Control of Hydraulic Turbine Generators Using Exact Feedback Linearization. 8th IEEE International Conference on Control and Automation Xiamen, China, June 9-11, 2010.

[14] Tin Win Mon, and Myo Myint Aung. Simulation of Synchronous Machine in Stability Study for Power System World Academy of Science, Engineering and Technology 39 2008).

[15] Innocent Kamwa, Daniel Lefebvre and Lester Loud, Member, IEEE, Small Signal Analysis of Hydro-Turbine Governors in Large Interconnected Power Plants, 0-7803-7322-7/02/\$17.00 @ 2002 IEEE.

[16] Li Wang, Senior Member, IEEE, Dong-Jing Lee, Jian-Hong Liu, Zan-Zia Chen, Zone-Yuan Kuo, Huei-Yuan Jang, Jiunn-Ji You, JinTsang, Tsai, Ming-Hua Tsai, Wey-Tau Lin, and Yeun-Jong Lee. Installation and Practical Operation of the First Micro Hydro Power System in Taiwan Using Irrigation Water in an Agriculture Canal. (02008 IEEE

[17] Fang Yang Hao Lei Yuanzhang Sun Wei Lin and Tielong Shen, Control of Hydraulic Turbine Generators Using Exact Feedback Linearization. 2010 8th IEEE International Conference on Control and Automation Xiamen, China, June 9-11, 2010.

[18] Shahram Jadid and Abolfazl Salami Accurate Model of Hydroelectric Power Plant for load pickup during Power System restoration. $0-7803-8560-8 / 04 / \$ 20.00 \odot 2004 I E E E$.

[19] Tin Win Mon, and Myo Myint Aung. Simulation of Synchronous Machine in Stability Study for Power System. World Academy of Science, Engineering and Technology 392008

[20] www.mathworks.com

[21] Yi-jian LIU†1, Yan-jun FANG2, Xue-mei ZHU1. Modeling of hydraulic turbine systems based on a Bayesian-Gaussian neural network driven by sliding window data. Journal of Zhejiang University-SCIENCE C (Computers \& Electronics) ISSN 1869-1951 (Print); ISSN 1869-196X (Online).

[22] Cédric JOIN_,Gérard ROBERT and Michel FLIESS. Model-Free Based Water Level Control for Hydroelectric Power Plants. Author manuscript, published in "IFAC Conference on Control Methodologies and Tecnologies for Energy Efficiency (CMTEE) (2010)".

[23] Peter Goodwin, Klaus Jorde, Claudio Meier and Oscar Parra. Minimizing environmental impacts of hydropower development: transferring lessons from past projects to a proposed strategy for Chile. doi: 10.2166/hydro.2006.005

[24] M. Aktarujjaman, M.A. Kashem, M. Negnevitsky. Dynamics of a Hydro-Wind Hybrid Isolated Power System. School of Engineering University of Tasmania Tasmania, Australia mda0@utas.edu.au 